\title{
An approach to the care of patients with irritable bowel syndrome
}

\author{
Adam D. Farmer PhD, Emma Wood PhD, James K. Ruffle MBBS
}

Cite as: CMAJ 2020 March 16;192:E275-82. doi: 10.1503/cmaj.190716

CMAJ Podcasts: author interview at https://soundcloud.com/cmajpodcasts/190716-view

I rritable bowel syndrome (IBS) is a disorder of gut-brain interaction (previously referred to as a functional gastrointestinal disorder), characterized by abdominal pain associated with a change in frequency or form of bowel habit. Irritable bowel syndrome accounts for more than $40 \%$ of new referrals to gastroenterology outpatient clinics, although the disease is mostly managed by primary care practitioners. ${ }^{1-3}$ We summarize the epidemiology, pathophysiology, differential diagnosis and management of IBS, drawing on best available evidence (Box 1) to guide family physicians and nonspecialists in management of this condition.

\section{What is the burden of IBS?}

Irritable bowel syndrome is common, affecting $3.7 \%$ of men and $7.8 \%$ of women in Canada, with a peak incidence in ages 18-34 years. ${ }^{4}$ The incidence of IBS has been reported to be about 4 new cases per 1000 patients per year. ${ }^{5}$ In 2005, the annual direct medical costs of IBS per annum worldwide were estimated to be US\$1.5-\$10 billion, excluding over-the-counter and prescription medication costs. ${ }^{1}$ Irritable bowel syndrome is also associated with increased work absenteeism and poor work productivity because of symptoms, with associated annual costs to employers of Can $\$ 2200$ per patient. ${ }^{6}$

\section{Which clinical features typify IBS?}

The diagnosis of IBS is symptom-based. The diagnostic criteria are recurrent abdominal pain (occurring on average at least 1 day per week in the previous 3 months, with the onset of symptoms occuring at least 6 months before diagnosis) with at least 2 of the following: related to defecation, associated with a change in stool frequency, and associated with a change in stool appearance. ${ }^{1}$ Patients with IBS usually present with symptoms of recurrent abdominal pain and a change in stool form or frequency. ${ }^{1}$ Stool changes can manifest as diarrhea or constipation or an alternation between the two. Abdominal pain is frequently associated with defecation. Extragastrointestinal symptoms are also common and include headache, dysmenorrhea, dyspareunia and fatigue. Irritable bowel syndrome frequently occurs in

\section{KEY POINTS}

- Irritable bowel syndrome (IBS) is a common disorder characterized by chronic abdominal pain that is associated with a change in frequency or form of bowel habit.

- The underlying pathophysiology of IBS is incompletely understood.

- The differential diagnosis of IBS is broad and, in conjunction with targeted investigations, the diagnosis is symptom-based.

- The syndrome can be usefully subdivided according to its predominant bowel habit.

- Treatments are multifaceted; they include education and reassurance, dietary modifications and pharmaceutical interventions, largely directed toward improving the most bothersome symptoms.

patients with other medically unexplained or affective disorders, such as fibromyalgia, depression or anxiety. ${ }^{7}$ Furthermore, patients with IBS may have other overlapping disorders of gutbrain interaction, such as functional dyspepsia. ${ }^{8}$ Symptoms typically vary in frequency and intensity, and are often aggravated by stress. ${ }^{9}$

The Rome Foundation (https://theromefoundation.org/ about) has sought to systematize, evaluate and revise the definition of IBS using a multinational expert process. The current Rome IV classification is the culmination of the evolution of a series of iterations (Rome I-Rome III). ${ }^{1}$ The Rome criteria currently divide IBS into 4 subtypes based on the most prominent bowel habit: IBS with constipation (IBS-C), IBS with diarrhea (IBS-D), IBS with mixed bowel habit (IBS-M; with alternating between constipation and diarrhea) and IBS unclassified (IBS-U) (Figure 1). ${ }^{1}$ The most frequent subtype is IBS-D, accounting for about $40 \%$ of patients. ${ }^{10}$ Although IBS in general is more common among women, IBS-D is more common among men. ${ }^{10}$ There are considerable geographic and ethnic differences in health care seeking that affect epidemiological estimates. ${ }^{10} \mathrm{~A}$ population-based study showed that health care seeking was independently associated with severity and duration of the pain rather than psychological factors. ${ }^{11}$ 


\section{Box 1: Literature search}

We searched PubMed (1946-September 2019), Embase and Embase Classic (1947-September 2019), and the Cochrane Central Register of Controlled Trials using the terms "irritable bowel syndrome" and "IBS," both on their own and with the AND function, including the terms "pathophysiology," "treatment" and "drugs." We drew on relevant research conducted in human adult populations, focusing mainly on guidelines, meta-analyses and clinical trials.

\section{What causes IBS?}

The condition is currently considered to be a manifestation of bidirectional disordered communication within the brain-gut axis that influences gastrointestinal motility, secretion and sensation. ${ }^{12}$ Within this construct, a number of elements such as genetic factors, ${ }^{13}$ personality traits, ${ }^{14}$ alterations in the stress-responsive physiologic systems, ${ }^{15}$ low-grade gastrointestinal inflammation, ${ }^{16}$ changes within the microbiota ${ }^{17}$ and the sequelae of enteric infections (termed postinfectious IBS), ${ }^{18}$ have all been proposed as being important in the development and maintenance of the disorder ${ }^{19}$ (Figure 2). However, the pathophysiology of IBS is not fully understood.

\section{Which differential diagnoses should be considered before making a diagnosis of IBS?}

Given the relative lack of symptom specificity, the differential diagnosis of IBS is broad and includes inflammatory bowel disease (IBD), celiac disease, bile acid diarrhea and carbohydrate

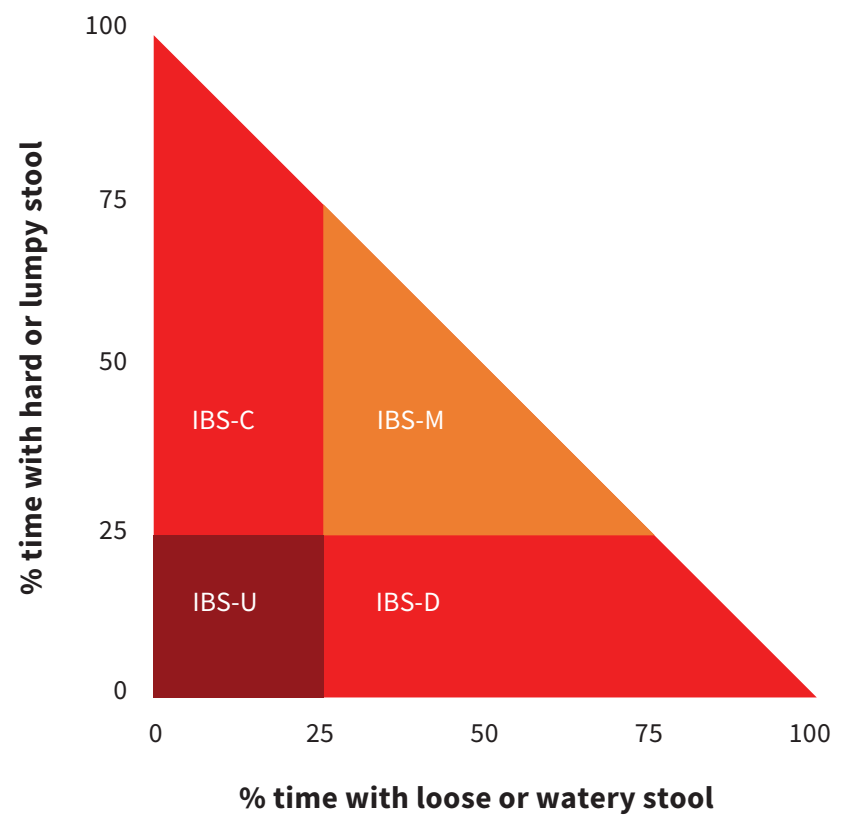

Figure 1: Classification of the different subtypes of inflammatory bowel disease (IBS) according to the predominant bowel habit: IBS with constipation (IBS-C), IBS with diarrhea (IBS-D), IBS with mixed bowel habit (IBS-M) and IBS unclassified (IBS-U). malabsorption (e.g., lactose intolerance) ${ }^{21}$ It is important to exclude serious conditions by looking specifically for "alarm symptoms" or "red flags" that may indicate neoplasm, including those listed in Box 2. However, using the diagnostic criteria mentioned above, and in the absence of red flag symptoms, IBS can be diagnosed without the need for extensive investigations. ${ }^{22}$ In patients with IBS-D, complete blood count, inflammatory markers (e.g., C-reactive protein), ferritin, vitamin $B_{12}$, folate and celiac serologic (immunoglobulin A tissue transglutaminase) testing are helpful to exclude iron deficiency anemia, malabsorption and celiac disease. A 2015 meta-analysis of studies of diagnostic tests found that a normal fecal calprotectin level has a high negative predictive value for IBD, ${ }^{23}$ although absolute cut-off values vary from assay to assay and from laboratory to laboratory.

The symptoms of bile acid diarrhea are indistinguishable from IBS-D, and about $30 \%$ of patients who meet the Rome criteria for IBS-D have bile acid diarrhea. ${ }^{24}$ Depending on local availability of tests, bile acid diarrhea can be diagnosed using investigations such as 23-seleno-25-homo-taurocholic acid (SeHCAT) nuclear medicine testing, serum 7 - $\alpha$-hydroxy-4-cholesten-3-one (C4) or measurement of fecal bile acids. It is important to consider this differential in patients who have undergone cholecystectomy, as bile acid diarrhea frequently responds to bile acid sequestrants, such as cholestyramine or colesevelam. For IBS-C, a detailed history needs to be taken to exclude secondary causes of constipation (e.g., diuretics, opioids and drugs with an anticholinergic mechanism of action).

\section{How is IBS managed?}

The clinical management of IBS can be challenging. Developing a positive therapeutic relationship with patients, underpinned by patient education, is key to optimizing clinical outcomes. ${ }^{25}$ Managing the bothersome symptoms is the mainstay of IBS treatment. When the condition is difficult to manage, care by a multidisciplinary team that includes specialist nurses, dietitians, liaison psychiatrists and psychologists can improve outcomes, although access to such services markedly depends on local service provision. ${ }^{26}$ Comprehensive guidelines regarding the management of IBS are available from the Canadian Digestive Health Foundation and the American College of Gastroenterology. ${ }^{6,26} \mathrm{~A}$ summary management algorithm is shown in Figure 3.

Broadly, clinicians should conduct a careful and detailed evaluation of symptom onset and the effect on the patient's quality of life, and explain that the diagnosis is symptom-based, that multiple investigations are not usually needed and that targeted treatment can improve quality of life. It is important to explain that IBS is a relapsing and remitting disorder in which the predominant bowel habit and symptoms can change over time, that it is not a progressive inflammatory disorder like inflammatory bowel disease (with which patients may confuse it), and that cancer is unlikely in the absence of red flag symptoms. Physicians may direct patients to reliable online sources of information and peer-group support, such as the Canadian Society of Intestinal Research and the IBS Network. 


\section{Lifestyle and dietary interventions}

The guideline from the American College of Gastroenterology states that increasing exercise can lead to overall symptom improvement in IBS, although the evidence for this recommendation is weak. ${ }^{26}$ Studies suggest that $70 \%-84 \%$ of patients with IBS report that certain food groups exacerbate their symptoms and dietary modifications can be useful. ${ }^{28,29}$

A number of randomized controlled trials (RCTs) have examined the effects on IBS of reducing dietary intake of fermentable oligo-, di-, monosaccharides and polyols (FODMAP) - fermentable carbohydrates that are thought to cause an osmotic effect and increase intracolonic fermentation to cause gaseous distension. ${ }^{30,31}$ Food groups that are high in FODMAPs include legumes, fruits (e.g., apples, peaches) and artificial sweeteners. A 2018 meta-analysis that evaluated the efficacy of a diet low in FODMAPs in the treatment of IBS found that reducing FODMAP intake reduced global symptoms in the short term (relative risk [RR] 0.69, 95\% confidence interval [Cl] 0.540.88 ); however, the studies were of variable quality. ${ }^{32}$ Use of the low-
Box 2: Alarm, or red flag, features that would prompt the clinician to consider further investigations

- First presentation at age $>50 \mathrm{yr}$

- Weight loss

- Rectal bleeding or masses

- Nocturnal symptoms

- History of recent antibiotic use

- Raised inflammatory markers

- Family history of colorectal carcinoma

FODMAP diet as first-line therapy in IBS is controversial, as many studies showing the efficacy of the diet are of limited generalizability, did not use an appropriate comparator, lacked blinding and were of a short duration. ${ }^{33}$ Moreover, there are few studies objectively evaluating the efficacy of the low-FODMAP intervention in different

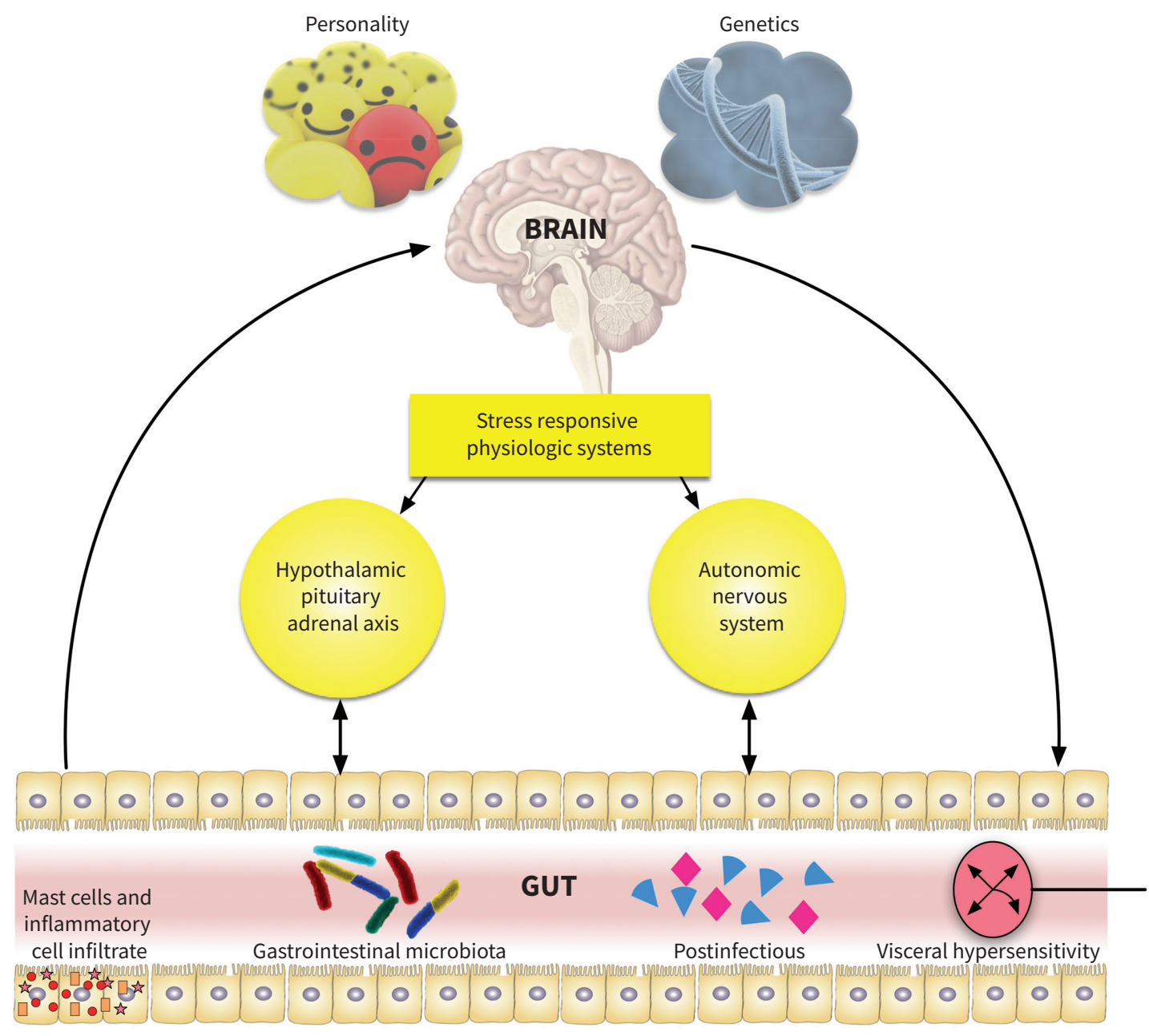

Figure 2: A schematic summary of the factors that have been implicated in the pathophysiology of irritable bowel syndrome (IBS) within the context of the brain-gut axis. This figure also demonstrates the concept of visceral hypersensitivity in IBS, in which the pain threshold to rectosigmoid mechanical distension is lower in patients with IBS than in healthy controls, suggesting that the viscera are more sensitive. ${ }^{20}$ 
subgroups of IBS. Given the complexities of this dietary intervention, we suggest that it should be instituted and monitored by a registered dietician with training and skills in this area.

\section{Pharmacologic treatment}

Pharmacologic therapies, which are directed at reducing symptoms such as constipation, diarrhea, bloating or pain, are summarized in Table 1.

\section{Constipation}

A 2016 meta-analysis of both randomized and observational studies of fibre supplementation in patients with IBS-C found that psyllium (ispaghula), a poorly fermented soluble fibre, is associated with an overall improvement in IBS and is moderately effective in managing constipation, although it is associated with gastrointestinal adverse effects, such as bloating. ${ }^{34}$ Insoluble fibre, such as bran, has not been shown to have a beneficial effect in IBS. ${ }^{26}$ In

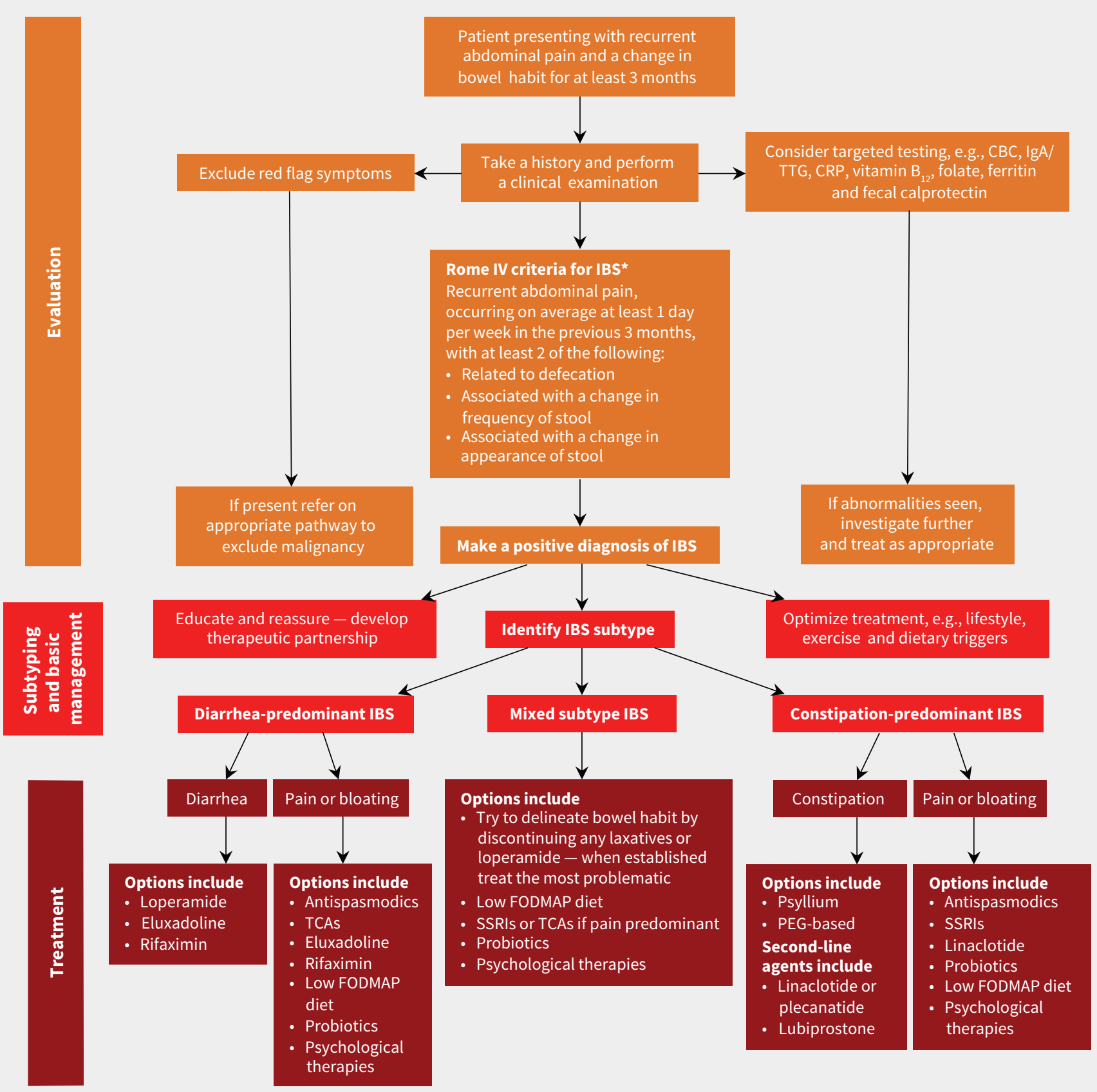

Figure 3: A suggested algorithm for the management of irritable bowel syndrome (IBS). Care is ideally personalized based on predominant symptom, patient preference and local availability. ${ }^{27}{ }^{*}$ Criteria fulfilled with symptom onset at least 6 months before diagnosis. Note: CBC = complete blood count; $\mathrm{CRP}=\mathrm{C}$-reactive protein; FODMAP = fermentable oligo-, di-, mono-saccharides and polyols; IgA/TTG = immunoglobulin A tissue transglutaminase; PEG = polyethylene glycol; SSRI = selective serotonin reuptake inhibitor; TCA = tricyclic antidepressant. 
many patients, the addition of simple laxatives, such as preparations containing polyethylene glycol, may be effective in improving stool frequency and consistency. ${ }^{26}$ Lactulose can worsen distension and bloating, and therefore can exacerbate abdominal pain. ${ }^{35}$ Linaclotide and plecanatide are guanylate cyclase- $\mathrm{C}$ agonists and are second-line therapies in IBS-C when simple laxatives have provided insufficient relief of symptoms. ${ }^{36}$ In addition to their laxative effect, guanylate cyclase- $\mathrm{C}$ agonists have the benefit of improving abdom- inal pain and bloating. ${ }^{37,38}$ Lubiprostone is a derivate of prostaglandin E1 that causes activation of the intestinal chloride channel type 2 on the intraluminal aspect of enterocytes. This results in chloride, and subsequently water, efflux into the intestinal lumen, leading to more watery stools. Lubiprostone has been shown to have a beneficial effect on stool consistency and abdominal pain in short-term use (1 month) but does not outperform placebo, except in abdominal bloating, at 3 months. ${ }^{39}$

Table 1: Summary of the currently available pharmaceutical treatment options for irritable bowel syndrome ${ }^{26}$

\begin{tabular}{|c|c|c|c|c|c|c|}
\hline $\begin{array}{l}\text { Treatment, by } \\
\text { symptom }\end{array}$ & Mechanism of action & Dosage & Adverse effects & $\begin{array}{l}\text { Relative risk of } \\
\text { remaining } \\
\text { symptomatic } \\
(95 \% \mathrm{Cl})\end{array}$ & $\begin{array}{l}\text { No. needed to } \\
\text { treat }(95 \% \mathrm{Cl})\end{array}$ & $\begin{array}{c}\text { Relative } \\
\text { cost* }^{\star}\end{array}$ \\
\hline \multicolumn{7}{|l|}{ Constipation } \\
\hline $\begin{array}{l}\text { Psyllium } \\
\text { (ispaghula) }\end{array}$ & Bulk forming & $\begin{array}{l}1 \text { sachet }(3.5 \mathrm{~g}) \\
\text { per day }\end{array}$ & $\begin{array}{l}\text { Bloating, abdominal } \\
\text { discomfort, diarrhea }\end{array}$ & $0.83(0.73-0.94)$ & $7(4-25)$ & $\$$ \\
\hline Linaclotide & $\begin{array}{l}\text { Guanylate cyclase-C } \\
\text { agonist }\end{array}$ & $\begin{array}{c}290 \mu \text { g once per } \\
\text { day }\end{array}$ & $\begin{array}{l}\text { Diarrhea, abdominal } \\
\text { discomfort, gas, bloating }\end{array}$ & $0.81(0.77-0.85)$ & $6(5-8)$ & $\$ \$$ \\
\hline Plecanatide & $\begin{array}{l}\text { Guanylate cyclase-C } \\
\text { agonist }\end{array}$ & $\begin{array}{c}3 \text { mg once per } \\
\text { day }\end{array}$ & Diarrhea & $0.88(0.84-0.92)$ & $10(8-14)$ & $\$ \$$ \\
\hline Loperamide & $\begin{array}{l}\mu \text {-Opioid receptor } \\
\text { agonist }\end{array}$ & $\begin{array}{l}2-4 \text { mg up to } \\
3 \text { times per day }\end{array}$ & $\begin{array}{l}\text { Constipation, } \\
\text { abdominal pain }\end{array}$ & $0.44(0.14-1.52)$ & Unknown & $\$$ \\
\hline Eluxadoline† & $\begin{array}{l}\text { Mixed } \mu \text {-opioid receptor } \\
\text { and } k \text {-opioid receptor } \\
\text { agonist, and } \delta \text {-opioid } \\
\text { receptor antagonist }\end{array}$ & $\begin{array}{l}\text { 75-100 mg } \\
\text { twice per day }\end{array}$ & $\begin{array}{l}\text { Constipation, } \\
\text { abdominal pain, } \\
\text { pancreatitis }\end{array}$ & $0.91(0.85-0.97)$ & $12.5(8-33)$ & $\$ \$$ \\
\hline \multicolumn{7}{|l|}{ Pain } \\
\hline $\begin{array}{l}\text { Antispasmodics } \\
\text { (e.g., pinaverium) }\end{array}$ & $\begin{array}{l}\text { Smooth muscle } \\
\text { relaxant - calcium } \\
\text { channel blocker }\end{array}$ & $\begin{array}{l}50-100 \mathrm{mg} \text { once } \\
\text { or twice per day }\end{array}$ & $\begin{array}{l}\text { Stomach pain, fullness, } \\
\text { nausea }\end{array}$ & $0.65(0.56-0.76)$ & $5(4-8)$ & $\$$ \\
\hline \multicolumn{7}{|c|}{ Modification of the microbiota } \\
\hline Rifaximin & $\begin{array}{l}\text { Poorly absorbed } \\
\text { antibiotic }\end{array}$ & $\begin{array}{l}550 \text { mg twice } \\
\text { per day for } \\
14 \text { days }\end{array}$ & $\begin{array}{l}\text { Nausea, vomiting, } \\
\text { constipation }\end{array}$ & $0.86(0.81-0.91)$ & $10.5(8-16)$ & $\$ \$$ \\
\hline Probiotics & $\begin{array}{l}\text { Regulation of intestinal } \\
\text { microbial homeostasis, } \\
\text { gut mucosal barrier } \\
\text { function }\end{array}$ & $\begin{array}{l}\text { Varies } \\
\text { depending on } \\
\text { preparation }\end{array}$ & Gas and bloating & $0.81(0.74-0.88)$ & $7(5-12)$ & $\$ \$$ \\
\hline
\end{tabular}




\section{Diarrhea}

Loperamide is an opioid receptor agonist that does not cross the blood-brain barrier, and hence does not exert an analgesic effect. Using this opioid effect, there is a reduction in colonic motility, which allows an increased quantity of water to be reabsorbed from colonic contents. In turn, this results in hard, drier stools and diminished defecatory urgency. Although adverse events with loperamide are rare, some patients may develop constipation, which can be avoided using dose titration with liquid formulations. An alternative is eluxadoline, a $\mu$ and $\kappa$-opioid receptor agonist and $\delta$-opioid receptor antagonist, which has been shown to improve stool consistency and reduce abdominal pain, although it is contraindicated in patients who have had a prior cholecystectomy. ${ }^{40,41}$ The 5-hydroxytryptamine type $3\left(5-\mathrm{HT}_{3}\right)$ receptor antagonists may also be effective in the management of IBS-D. Serotonin (5-HT) is a major mediator of afferent nerve signalling and exerts a prokinetic effect within the gut, with $5-\mathrm{HT}_{3}$ receptor antagonists blocking vagal induction of 5-HT. Irritable bowel syndrome with diarrhea has been associated with several 5-HT abnormalities within the gut, including heightened numbers of 5-HT-containing enteroendocrine cells, ${ }^{42}$ increased postprandial 5-HT release ${ }^{43}$ and reduced serotonin transporter messenger RNA in the colon. ${ }^{44,45}$ Previously, alosetron, a $5-\mathrm{HT}_{3}$ receptor antagonist, was approved for use in IBS-D, although it is not available in Canada because of cases of ischemic colitis. ${ }^{46}$ Studies are ongoing to evaluate ondansetron, which is typically used as an antiemetic in IBS-D.

\section{Pain}

Effectively managing abdominal pain in IBS can be challenging. Current pharmacologic options including antispasmodics, and low-dose tricyclic antidepressants (TCAs) and selective serotonin reuptake inhibitors (SSRIS). The broad mechanism of action of antispasmodics is to induce muscular relaxation of the wall of the gastrointestinal tract. Hyoscine reduces acetylcholine binding at muscarinic receptors, which results in smooth muscle relaxation, although it can worsen constipation. Calcium channel blockers, such as pinaverium, also reduce smooth muscle contraction, and preparations containing peppermint oil can reduce symptoms. ${ }^{47}$ Mebeverine, a musculotropic agent that reduces intestinal peristalsis, has been shown to reduce symptom burden in non-placebo-controlled studies. ${ }^{48}$ The mechanism of action of TCAs and SSRIs is incompletely understood, but it is thought that they influence the afferent barrage of nociceptive signalling at the level of the spinal dorsal horn and influence descending modulatory pain pathways. ${ }^{21,49}$ In addition, TCAs and SSRIs may positively affect comorbid anxiety and depression. Overall, meta-analytic evidence suggests that antidepressants are efficacious in managing IBS..$^{50}$ The most frequently used TCA is low-dose amitriptyline (e.g., $10 \mathrm{mg}$ at night), which can be titrated up. Tricyclic antidepressants have a number of anticholinergic adverse effects, which include constipation and are therefore most suitable for patients with IBS-D. In contrast, SSRIs can cause diarrhea and therefore may be considered in patients with IBS-C.

\section{Interventions targeting the microbiota}

Given the proposed role of the microbiota in the pathophysiology of IBS, several studies have evaluated the role of interventions that modify the microbiota. For instance, a large placebocontrolled trial of rifaximin, a minimally absorbed antibiotic, has shown significant symptomatic improvement in patients with IBS who received treatment with rifaximin, although the number needed to treat was $10.6 .^{51,52} \mathrm{~A}$ further study has evaluated the safety and efficacy of repeated treatment with rifaximin. ${ }^{53}$ Among patients who clinically responded to open-label treatment, about two-thirds experienced a relapse and were randomly assigned to receive repeat treatment with rifaximin or placebo. There was a small but statistically significant response in the group receiving treatment with rifaximin compared with the placebo group ( $38.1 \%$ v. $31.5 \%, p=0.03$ ), with the best response seen with respect to abdominal pain. ${ }^{33} \mathrm{~A}$ number of studies have provided evidence to support the role of probiotics in IBS, although variations in study design and specific probiotics used limit interpretability. ${ }^{54-56}$ Nevertheless, a proportion of patients derive benefit from probiotics and a pragmatic approach is to institute a month trial.

\section{Psychological therapies}

As a class of interventions, psychological treatments are effective in reducing overall symptom burden in IBS (RR 0.69, 95\% $\mathrm{Cl} 0.62-$ 0.76) according to a meta-analysis of RCTs, although the quality of the evidence is weak owing to study heterogeneity. ${ }^{50}$ Several techniques, including cognitive behavioural therapy (CBT), dynamic psychotherapy and hypnotherapy have been shown to be effective, as summarized in a recent review. ${ }^{57}$ Psychological therapies should be considered for patients who have not responded to first- or second-line treatments after 3-6 months, or in whom there is a significant association between stress and symptoms, according to a recent international expert consensus. ${ }^{27}$ In a 2008 RCT of self-administered CBT or psychotherapistdelivered CBT compared with usual care in patients with moderate to severe IBS, either form of CBT was found to improve quality of life and reduce IBS symptom severity in comparison with usual care. ${ }^{58} \mathrm{~A}$ case-control study found that gut-focused hypnotherapy, a technique that uses suggestion, imagery and relaxation directed toward the gastrointestinal tract, reduces gastrointestinal symptoms, putatively via changes in cognitive function leading to a reduction in visceral sensitivity. ${ }^{59}$ In a recent report of an audit of 1000 patients with IBS, hypnotherapy was associated with reduced abdominal pain, and improvements in symptoms and quality of life. ${ }^{60}$ Despite this evidence, the utility of psychological interventions in IBS is limited by availability of expert therapists.

\section{Conclusion}

Irritable bowel syndrome is a prevalent and multifactorial disorder whose pathophysiology remains incompletely understood. Diagnosis relies on the identification of chronic typical symptoms characterized by abdominal pain, bloating and change in frequency or form of bowel habit. Although IBS is conventionally 
subclassified according to predominant bowel habit, the syndrome likely encompasses a number of distinct pathophysiologies that result in similar clinical phenotypes. While several management options exist, further work is needed to individualize therapy, which may result in improved outcomes.

\section{References}

1. Mearin F, Lacy BE, Chang L, et al. Bowel disorders. Gastroenterology 2016 Feb. 18 [Epub ahead of print]. doi: 10.1053/j.gastro.2016.02.031.

2. Hungin AP, Whorwell PJ, Tack J, et al. The prevalence, patterns and impact of irritable bowel syndrome: an international survey of 40,000 subjects. Aliment Pharmacol Ther 2003;17:643-50.

3. Corazziari E. Definition and epidemiology of functional gastrointestinal disorders. Best Pract Res Clin Gastroenterol 2004;18:613-31.

4. Palsson OS, van Tilburg M, Simren M, et al. Population prevalence of Rome IV and Rome III irritable bowel syndrome (IBS) in the United States (US), Canada and the United Kingdom (UK). Gastroenterology 2016;150(Suppl 1):S739-40.

5. Rodríguez LA, Ruigómez A. Increased risk of irritable bowel syndrome after bacterial gastroenteritis: cohort study. BMJ 1999;318:565-6.

6. Fedorak RN, Vanner SJ, Paterson WG, et al. Canadian Digestive Health Foundation Public Impact Series 3: irritable bowel syndrome in Canada. Incidence, prevalence, and direct and indirect economic impact. Can J Gastroenterol 2012;26:252-6.

7. Hausteiner-Wiehle C, Henningsen P. Irritable bowel syndrome: relations with functional, mental, and somatoform disorders. World J Gastroenterol 2014;20: 6024-30.

8. Wang $A$, Liao X, Xiong $L$, et al. The clinical overlap between functional dyspepsia and irritable bowel syndrome based on Rome III criteria. BMC Gastroenterol 2008;8:43.

9. Qin HY, Cheng CW, Tang XD, et al. Impact of psychological stress on irritable bowel syndrome. World J Gastroenterol 2014;20:14126-31.

10. Lovell RM, Ford AC. Effect of gender on prevalence of irritable bowel syndrome in the community: systematic review and meta-analysis. Am J Gastroenterol 2012;107:991-1000.

11. Talley NJ, Boyce PM, Jones M. Predictors of health care seeking for irritable bowel syndrome: a population based study. Gut 1997;41:394-8.

12. Farmer $A D, A z i z Q$. Visceral pain hypersensitivity in functional gastrointestinal disorders. Br Med Bull 2009;91:123-36.

13. Ek WE, Reznichenko A, Ripke S, et al. Exploring the genetics of irritable bowel syndrome: a GWA study in the general population and replication in multinational case-control cohorts. Gut 2015;64:1774-82.

14. Farnam A, Somi MH, Sarami F, et al. Five personality dimensions in patients with irritable bowel syndrome. Neuropsychiatr Dis Treat 2008;4:959-62.

15. Chang $L$. The role of stress on physiologic responses and clinical symptoms in irritable bowel syndrome. Gastroenterology 2011;140:761-5.

16. Akiho $\mathrm{H}$, Ihara $\mathrm{E}$, Nakamura K. Low-grade inflammation plays a pivotal role in gastrointestinal dysfunction in irritable bowel syndrome. World J Gastrointest Pathophysiol 2010;1:97-105.

17. De Palma G, Collins SM, Bercik P. The microbiota-gut-brain axis in functional gastrointestinal disorders. Gut Microbes 2014;5:419-29.

18. Marshall JK, Thabane M, Garg AX, et al.; Walkerton Health Study Investigators. Incidence and epidemiology of irritable bowel syndrome after a large waterborne outbreak of bacterial dysentery. Gastroenterology 2006;131:44550 , quiz 660 .

19. Camilleri M, Ford AC. Irritable bowel syndrome: pathophysiology and current therapeutic approaches. Handb Exp Pharmacol 2017;239:75-113.

20. Whitehead WE, Engel BT, Schuster MM. Irritable bowel syndrome: physiological and psychological differences between diarrhea-predominant and constipation-predominant patients. Dig Dis Sci 1980;25:404-13.

21. Farmer AD, Ruffle JK. Irritable bowel syndrome. Hamdan Med J 2015;8:265-78.

22. Ford AC, Bercik P, Morgan DG, et al. Validation of the Rome III criteria for the diagnosis of irritable bowel syndrome in secondary care. Gastroenterology 2013;145:1262-70.e1.
23. Menees SB, Powell C, Kurlander J, et al. A meta-analysis of the utility of $\mathrm{C}$-reactive protein, erythrocyte sedimentation rate, fecal calprotectin, and fecal lactoferrin to exclude inflammatory bowel disease in adults with IBS. Am J Gastroenterol 2015;110:444-54.

24. Slattery SA, Niaz O, Aziz Q, et al. Systematic review with meta-analysis: the prevalence of bile acid malabsorption in the irritable bowel syndrome with diarrhoea. Aliment Pharmacol Ther 2015;42:3-11.

25. Hulme K, Chilcot J, Smith MA. Doctor-patient relationship and quality of life in irritable bowel syndrome: an exploratory study of the potential mediating role of illness perceptions and acceptance. Psychol Health Med 2018;23:674-84.

26. Ford AC, Moayyedi P, Chey WD, et al.; ACG Task Force on Management of Irritable Bowel Syndrome. American College of Gastroenterology monograph on management of irritable bowel syndrome. Am J Gastroenterol 2018; 113(Suppl 2):1-18

27. Moayyedi P, Mearin F, Azpiroz F, et al. Irritable bowel syndrome diagnosis and management: a simplified algorithm for clinical practice. United European Gastroenterol J 2017;5:773-88.

28. Monsbakken KW, Vandvik PO, Farup PG. Perceived food intolerance in subjects with irritable bowel syndrome - etiology, prevalence and consequences. Eur J Clin Nutr 2006;60:667-72

29. Böhn L, Störsrud S, Törnblom H, et al. Self-reported food-related gastrointestinal symptoms in IBS are common and associated with more severe symptoms and reduced quality of life. Am J Gastroenterol 2013;108:634-41.

30. Murray K, Wilkinson-Smith V, Hoad C, et al. Differential effects of FODMAPs (fermentable oligo-, di-, mono-saccharides and polyols) on small and large intestinal contents in healthy subjects shown by MRI. Am J Gastroenterol 2014;109:110-9.

31. Tuck CJ, Muir JG, Barrett JS, et al. Fermentable oligosaccharides, disaccharides, monosaccharides and polyols: role in irritable bowel syndrome. Expert Rev Gastroenterol Hepatol 2014;8:819-34.

32. Dionne J, Ford AC, Yuan Y, et al. A systematic review and meta-analysis evaluating the efficacy of a gluten-free diet and a low FODMAPs diet in treating symptoms of irritable bowel syndrome. Am J Gastroenterol 2018;113:1290-300.

33. Hill P, Muir JG, Gibson PR. Controversies and recent developments of the lowFODMAP diet. Gastroenterol Hepatol (N Y) 2017;13:36-45.

34. Christodoulides S, Dimidi E, Fragkos KC, et al. Systematic review with metaanalysis: effect of fibre supplementation on chronic idiopathic constipation in adults. Aliment Pharmacol Ther 2016;44:103-16.

35. Portalatin M, Winstead N. Medical management of constipation. Clin Colon Rectal Surg 2012;25:12-9.

36. Sharma A, Herekar AA, Bhagatwala J, et al. Profile of plecanatide in the treatment of chronic idiopathic constipation: design, development, and place in therapy. Clin Exp Gastroenterol 2019;12:31-6.

37. Chey WD, Lembo AJ, Lavins BJ, et al. Linaclotide for irritable bowel syndrome with constipation: a 26-week, randomized, double-blind, placebo-controlled trial to evaluate efficacy and safety. Am J Gastroenterol 2012;107:1702-12.

38. Brenner DM, Fogel R, Dorn SD, et al. Efficacy, safety, and tolerability of plecanatide in patients with irritable bowel syndrome with constipation: results of two phase 3 randomized clinical trials. Am J Gastroenterol 2018;113:735-45.

39. Li F, Fu T, Tong WD, et al. Lubiprostone is effective in the treatment of chronic idiopathic constipation and irritable bowel syndrome: a systematic review and meta-analysis of randomized controlled trials. Mayo Clin Proc 2016;91:456-68.

40. Lembo AJ, Lacy BE, Zuckerman MJ, et al. Eluxadoline for irritable bowel syndrome with diarrhea. N Engl J Med 2016;374:242-53.

41. Lacy BE, Harris LA, Chang L, et al. Impact of patient and disease characteristics on the efficacy and safety of eluxadoline for IBS-D: a subgroup analysis of phase III trials. Therap Adv Gastroenterol 2019;12:1756284819841290.

42. Dunlop SP, Jenkins D, Neal KR, et al. Relative importance of enterochromaffin cell hyperplasia, anxiety, and depression in postinfectious IBS. Gastroenterology 2003;125:1651-9.

43. Dunlop SP, Coleman NS, Blackshaw E, et al. Abnormalities of 5-hydroxytryptamine metabolism in irritable bowel syndrome. Clin Gastroenterol Hepatol 2005;3: 349-57.

44. Foley S, Garsed K, Singh G, et al. Impaired uptake of serotonin by platelets from patients with irritable bowel syndrome correlates with duodenal immune activation. Gastroenterology 2011;140:1434-43.e1. 
45. Faure C, Patey N, Gauthier C, et al. Serotonin signaling is altered in irritable bowel syndrome with diarrhea but not in functional dyspepsia in pediatric age patients. Gastroenterology 2010;139:249-58.

46. Chang L, Chey WD, Harris L, et al. Incidence of ischemic colitis and serious complications of constipation among patients using alosetron: systematic review of clinical trials and post-marketing surveillance data. Am J Gastroenterol 2006;101:1069-79.

47. Enck P, Aziz Q, Barbara G, et al. Irritable bowel syndrome. Nat Rev Dis Primers 2016;2:16014.

48. Annaházi A, Róka R, Rosztóczy A, et al. Role of antispasmodics in the treatment of irritable bowel syndrome. World J Gastroenterol 2014;20:6031-43.

49. Farmer $A D$, Aziz Q. Mechanisms and management of functional abdominal pain. J R Soc Med 2014;107:347-54.

50. Ford AC, Lacy BE, Harris LA, et al. Effect of antidepressants and psychological therapies in irritable bowel syndrome: an updated systematic review and meta-analysis. Am J Gastroenterol 2019;114:21-39.

51. Pimentel M, Lembo A, Chey WD, et al.; TARGET Study Group. Rifaximin therapy for patients with irritable bowel syndrome without constipation. $N$ Engl J Med 2011;364:22-32.

52. Shah E, Kim S, Chong K, et al. Evaluation of harm in the pharmacotherapy of irritable bowel syndrome. Am J Med 2012;125:381-93.

53. Lembo A, Pimentel M, Rao SS, et al. Repeat treatment with rifaximin is safe and effective in patients with diarrhea-predominant irritable bowel syndrome. Gastroenterology 2016;151:1113-21.

54. Moayyedi P, Ford AC, Talley NJ, et al. The efficacy of probiotics in the treatment of irritable bowel syndrome: a systematic review. Gut 2010;59:325-32.

55. Ford AC, Talley NJ. Irritable bowel syndrome. BMJ 2012;345:e5836.

56. Didari T, Mozaffari S, Nikfar S, et al. Effectiveness of probiotics in irritable bowel syndrome: updated systematic review with meta-analysis. World J Gastroenterol 2015;21:3072-84.
57. Palsson OS, Whitehead WE. Psychological treatments in functional gastrointestinal disorders: a primer for the gastroenterologist. Clin Gastroenterol Hepatol 2013;11:208-16; quiz e22-3.

58. Lackner JM, Jaccard J, Krasner SS, et al. Self-administered cognitive behavior therapy for moderate to severe irritable bowel syndrome: clinical efficacy, tolerability, feasibility. Clin Gastroenterol Hepatol 2008;6:899-906.

59. Lea R, Houghton LA, Calvert EL, et al. Gut-focused hypnotherapy normalizes disordered rectal sensitivity in patients with irritable bowel syndrome. Aliment Pharmacol Ther 2003;17:635-42.

60. Miller V, Carruthers HR, Morris J, et al. Hypnotherapy for irritable bowel syndrome: an audit of one thousand adult patients. Aliment Pharmacol Ther 2015;41:844-55.

\section{Competing interests: None declared.}

This article was solicited and has been peer reviewed.

Affiliations: Department of Gastroenterology (Farmer, Wood), University Hospitals of North Midlands, Stoke-on-Trent, UK; Institute of Applied Clinical Science (Farmer), University of Keele, Keele, Staffordshire, UK; Centre for Neuroscience, Surgery and Trauma (Farmer, Ruffle), Blizard Institute, Wingate Institute of Neurogastroenterology, Barts and the London School of Medicine and Dentistry, Queen Mary University of London, London, UK

Contributors: All of the authors contributed to drafting the manuscript, revised it critically for important intellectual content, gave final approval of the version to be published and agreed to be accountable for all aspects of the work.

Correspondence to: Adam Farmer, Adam.Farmer@uhnm.nhs.uk 